\title{
Utilization of SPARK Science Learning System (SSLS) and its effect on science process skills of students in science
}

Ganeb, Maribel

Science Department, Andres Bonifacio Integrated School, Philippines (jumpahead19@yahoo.com) Montebon, Darryl Roy T.

Institute of Teaching and Learning, Philippine Normal University, Philippines (montebon.drt@pnu.edu.ph) Buzon, Olivia

Faculty of Science Technology and Mathematics, Philippine Normal University, Philippines (buzon.or@pnu.edu.ph)

\section{Abstract}

This study looked into the utilization of SPARK Science Learning System (SSLL) in Science Investigative processes to determine its effect in enhancing the integrated process skills of students. A quasi-experimental, pre-test and post-test, research design was utilized to investigate the hypotheses of this study. Two groups were randomly assigned to be the experimental (SSLS) and the conventional group. Both groups were taught using the same modules. However, the SSLS group utilized the SPARK Science Learning System. After the six-week exposure the data that had been gathered revealed that utilization of SSLS in a science class enabled students to develop better integrated science process skills.

Keywords: SPARK Science Learning System (SSLS); integrated science process skills; computer assisted instruction; educational technology; science education 


\section{Utilization of SPARK Science Learning System (SSLS) and its effect on science process skills of students in science}

\section{Introduction}

The new generation of learners is technologically adapted individuals. Thus, integration of technology as an instructional tool has become a necessity in the teaching and learning processes (Morales, 2014). Technological applications in education have improved in various ways. Different software programs for concepts, animations and experiment simulations are examples of the use of technological equipment in education (Yesilyurt, 2011). Technology assists teachers and students attain successful learning (Valdez, 2005). Using technological equipment to form permanent learning has become a common method in educational areas around the world. However, to attain success in technology integration in education requires educators to combine strong content knowledge with appropriate pedagogical strategy (Mishra \& Kohler, 2006). Integrating technology into the curriculum and instruction bring about significant student achievement, deep understanding of concepts and positive impact on student (Clark, 2010). The aim of science education is to help students understand scientific knowledge and to develop students' ability to respond in scientific inquiry based approach of instruction. One of the factors that could develop the science inquiry skill of learners is to acquire a strong foundation in their science process skills.

Scientific process skills (SPS) are skills exemplified by scientific literate individuals. Therefore, these skills affect the personal, social, and global lives of individuals. These skills can be gained by students through certain science education activities (Huppert, Lomask \& Lazarorcitz, 2002). These complex yet coherent science process skills are otherwise known as integrated science process skills. Learners are expected to possess these skills as they progress to a higher grade level (Hafizan \& Shahali, 2010). Integrated science process skills could not be acquired immediately. Teachers could not expect students to excel at skills they have not experienced or been allowed to practice (Padilla, 1990). Teachers need to select curricula which emphasize the enhancement of science process skills. In addition, teachers need to capitalize on opportunities in the activities normally done in the classroom. While it is an easy to implement, it is deemed necessary because of the lack of emphasis of process skills in most commercial materials. The result of this research is helpful to the administrators and local officials in deciding whether to purchase or not this expensive learning gadget to assist the usual classroom situation, fill in the gap of students' comprehension and improve the quality of education of the learners. Moreover, the results of the present research will allow science teachers to decide whether to use or not the SPARK learning system.

\section{Review of Related Literature}

\subsection{Nature of Science Education at the Locale}

The K-12 framework in science education aims to develop scientific literacy among learners and mold them to participative citizens who are able to make judgments and decisions regarding applications of scientific knowledge that may have social, health, or environmental impacts. The science curriculum recognizes the place of science and technology in everyday human affairs. It integrates science and technology in the social, economic, personal and ethical aspects of life. The $\mathrm{K}$ to 12 science curriculum will provide learners with a repertoire of competencies important in the world of work and in a knowledge-based society (K-12 Curriculum Guide, 2013).

Student performance in science is low in the National Achievement Test(NAT). It has remained the lowest rank among all the five subjects as shown in the National Education Testing and Research Centre (DepEd, 
NETRC, 2014). Despite effort among schools administrators and teachers effort like conducting Saturday reviews and preparation of intervention materials, achievement test in science is still remarkably low. Mei and associates (2007) stated that the low achievement of student is hypothesized to be associated with students' integrated process skills. Hence, this study investigates another factor that should be given attention which is the acquisition of students integrated process skills.

With the desire to improve the performance of the students in the National Achievement Test (NAT), the local government of the City of Mandaluyong provided the school of the researcher a SPARK (See Perceive, Analzye, Reflect Know) Science Learning System (SSLS) with different sensors to further improve the learners' scientific ability and to deeply understand science concepts as well. The innovative device is hoped to be utilized by teachers as they teach science. Teachers are also expected to design effective classroom instruction to maximize the use of the SSLS.

\subsection{Science Process Skills and Student Achievement}

A recent report on science education in Europe (Osborne \& Dillon, 2008) recommends that the focus of science education for students in basic education should be on engaging students in scientific processes and phenomenon. This focus may be best achieved through activities that involve extended investigative work, actual experiments, and other forms of inquiry-oriented science activities. Researchers mapped the problems in science education and figured out why students still get unlikely performance in several appraising bodies. Prior reviews and studies depicted that teaching practices, poor expertise of teachers, ineffective teaching in science such as the lack of fit between the materials used in class, lack of inquiry-based science activities, negative perception to teachers and the subject were contributory factors why this happened (Fonseco \& Convoy, 2006). Many studies have analyzed the sources of the problem and these analyses have pointed out that an inadequate science curriculum (Bernardo, 2004) and poor preparation of teachers in terms of science content and pedagogy (Bernardo, 2002, 2004: Golla \& De Guzman, 1998).

In the hope to address these problems, several countries conducted studies on how their performance in science can be improved. Researchers found out that Computer Aided Instruction (CAI) can improve the performance of learners in science. CAI truly depicted its effectiveness to improve the performance of the learners (Hancer \& Tuzemen, 2008; Tabassum, 2001; Valdez, 2005; Yakar, 2005; Slagut, 2007). Such global realization is also being experienced in the Philippines. Thus, this research was undertaken. It is hoped that improving students' science process skills could lead them to be successful in their science classes. Research suggests that well-developed science process skills help science learners develop their self-efficacy in learning science as well as performing the experiments in different topics.(Padilla, 1990; Mei, et al., 2007). This variable is an essential field in science education that facilitate progress in the teaching and learning processes.

\subsection{SPARK Learning System}

See, Perceive, Analyze, Reflect, Know (SPARK) Science Learning System (SSLS) is a unified innovative teaching tool created in the 21st century. The SPARK Science learning system is a holistic portable device that integrates the power of probe ware with inquiry-based content and assessment. It is a device that includes a large, full-color display, finger-touch navigation and data collection and analysis capabilities designed to become a discovery-based science learning environment. It provides both the teacher and the students the embedded support for exploring science concepts. This tool allows the students to access anytime and anywhere in science discovery. (PASCO Data Logging, 2013) SPARK originally conceptualized and designed by PASCO, a trademark company in the United States of America. The company aimed to provide teachers and learners with computerized built in hands-on and inquiry based science learning packages. Initially, the company aimed to provide educators worldwide with innovative ways of teaching and learning processes in science (Stokstad, 2011). In the Philippines, this scientific learning tool has been introduced by Science Star Corporation. 
Utilization of technology based instructional tools is in demand in a science classroom. The Association for Educational Communications and Technology (AECT, 2003) defines educational technology as "the study and ethical practice of facilitating learning and improving performance by creating, using and managing appropriate technological processes and resources" (Richey, Silber, \& Ely, 2008). Inclusion of modern instrumentation indicated a positive change in students' perception in scientific ideas (Aurentz, Kerns \& Shibley, 2011). Computer assisted instruction has shown positive and large effect on the academic achievement of students in science education in Turkey (Hancer \&Tuzemen, 2008). Science educators in the world opted to teach science with computers since science has many theories and concepts which are difficult for the students to understand. Several researches recommend that practical works, hands on activities and the use of software in the classroom are necessary to completely assist students' performance (Valdez, 2005).

The curriculum design plays an important role in the acquisition of science process skills as suggested by the study of Mei in 2011.Integrated Science Process Skills (ISPS) should develop the $21^{\text {st }}$ century learners to become globally competitive individuals. These skills are a combination of the basic process skills in science like which are presumed to have been mastered in their formative years. These skills are describing, comparing, classifying, measuring and inferring (Mei et al., 2007).

\subsection{Conceptual Framework}

Figure 1 shows the conceptual framework of this study. As Morales (2014) insisted, SSLS must be meaningfully integrated to a curriculum so that its effectiveness would be noted. This study attempts to explore if utilization of SPARK Science Learning System in making students perform experiments on the science investigative process lessons can improve students' integrated science process skills.

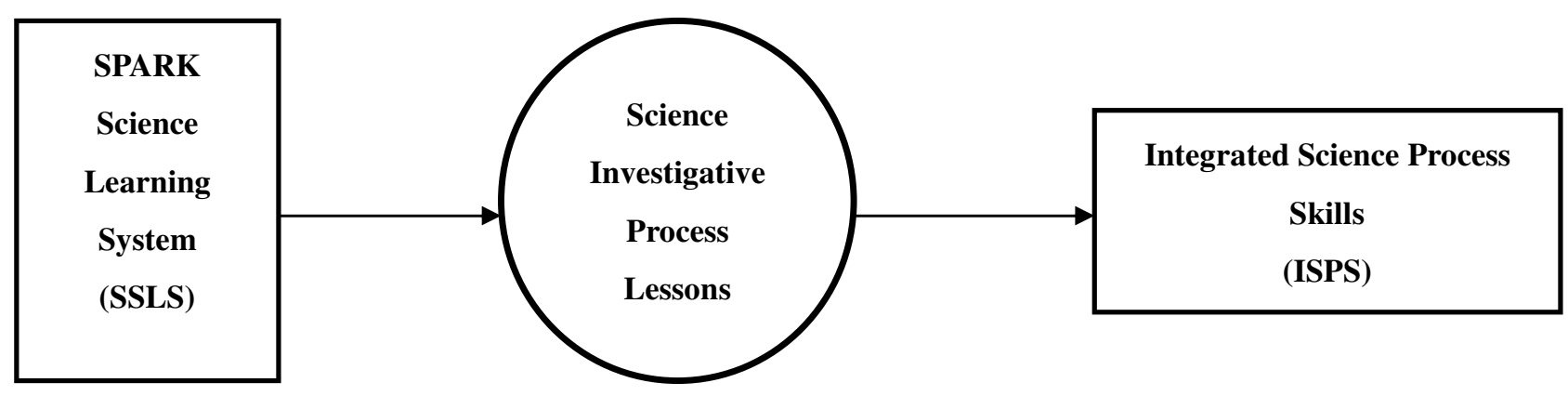

Figure 1. Conceptual Framework

\subsection{Research Problems}

This research aims to find out if the utilization of SSLS to Science Classes has a significant effect on the integrated science process skills of the learners. Specifically, this research aims to answer the following questions:

Is there a significant difference between the pre-test and post-test means of the students exposed to SSLS and the conventional method in their integrated science process skills?

$>$ Is the difference between the post-test means of the students exposed to SSLS and the conventional method in their integrated science process skills significant?

\section{Methodology}

Research Design - This study employed a quasi-experimental design research, specifically the Non-Equivalent Groups Design (NGED). NEGD is structured like a pretest-posttest non randomized experiment. 


\subsection{Participants}

The participants in this study were from the two sections of Grade 7 of Andres Bonifacio Integrated School Division of Mandaluyong City. A toss-coin technique was utilized to determine which section would be the SSLS group and the conventional group. Most of the respondents were ages 12-13 years old. Respondents were classified as heterogeneous groups whose general average during their $6^{\text {th }}$ grade ranges from $75-83 \%$. There were 87 respondents out of 450 population of Grade 7 students and out of 4000 school's population. The conventional group refers to the group of students who were taught without the use of the SSLS. On the other hand, the SSLS group is the experimental group since they were exposed to the teaching method being studied. The experimental group has 44 respondents from Grade 7 Charity and the control group has 43 respondents from Grade 7 Faith. The pre-test comparison between the SSLS and the conventional groups is shown in table below.

\subsection{Research Instrument}

To determine the integrated science process skills of the learners, a researcher made test was prepared by the researcher based on the grade- 7 modules. The said test focused on the two selected main topics from the $1^{\text {st }}$ quarter topics in Grade 7 Science Curriculum. Specifically, the themes were science investigative processes and diversity of materials on earth. The instrument was subjected to content and face validation by three science teachers, a master teacher, a head teacher and a university professor. Upon validation of the instrument, a mean score of 3.5 was obtained which could be interpreted that the questions are congruent with the objective or skill being measured.

Originally, a 50-item test was prepared to assess the students' skills in identifying the variables, formulating hypothesis, designing an experiment, acquiring the data from the table and analyzing the result of the given investigation. The instrument was subjected to content and face validation by three science teachers, a master teacher, a head teacher and a university professor. The validators' mean score on the released survey questionnaire was 3.5 which could be interpreted that the questions are congruent with the objective or skill being measured. The drafted instrument yielded a 0.70 Kuder-Richardson $\left(\mathrm{KR}_{20}\right)$ reliability coefficient. Such value suggests that the instrument made is reliable. The basis of reliability and the validity of the test was through Kuder-Richardson reliability coefficient, index of difficulty and the index of discrimination. After a trial to thirty grade 8 students, the researcher got the index of difficulty of the questionnaire and 40 items were chosen to be good items.

\subsection{Research Process}

Figure 2 describes the research process of this study.

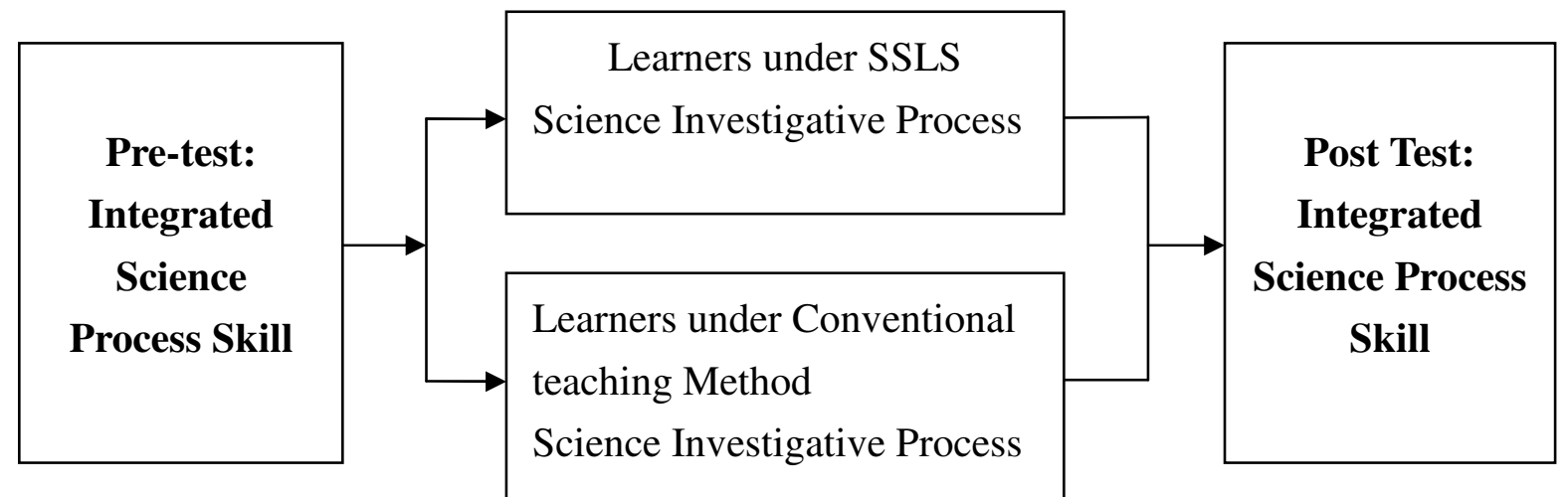

Figure 2. The Research Process

Prior to the intervention procedure, a pre-test was conducted among the conventional and the SSLS groups to test their ability in terms of the integrated science process skills. Table 1 below shows the result of the 
Ganeb, M., Montebon, D. R. T., \& Buzon, O.

comparison of their integrated science process skills ability.

\section{Table 1}

T-test comparison on the pre-test mean scores of the conventional and the SSLS groups

\begin{tabular}{lcccccc}
\hline Variable & Group & $\mathrm{N}$ & Mean & $\begin{array}{c}\text { Mean } \\
\text { Difference }\end{array}$ & t-value & p-value \\
\hline \multirow{2}{*}{ ISPS } & Conventional & 43 & 11.84 & 2.52 & 1.125 & 0.264 \\
& SSLS & 44 & 10.93 & & \\
\hline
\end{tabular}

Note. $p=0.05$

Table 1 shows the comparison between the pre-test mean of the conventional and the SSLS groups in the learners' Integrated Science Process Skills. The pre-test comparison of the ISPS of the participants had a p-value of 0.264 at the 0.05 level of significance. Results unfolded that there was no significant difference in their ISPS. It implies that both groups are comparable in terms of ISPS prior to the implementation of the learning instructions.

After which both groups were subject to classroom instruction utilizing their respective pedagogies. Lesson plans were prepared to ensure the parallelism of instruction and that the only difference both groups will experience is the utilization of the SSLS. The topics revolved around the theme diversity of materials on earth. The said topics had been taken from the released modules of the Department of Education in the Philippines. Specifically, these topics are:

$>\quad$ Dissolution rates

$>\quad$ Acids and Bases

$>\quad$ Effects of Acids and Bases

Prior to the intervention period, learners were oriented on how SSLS should be manipulated. During the experiments, the SSLS group utilized SSLS which is programmed in the Sparklab, $\mathrm{pH}$ and temperature sensors while the rest were materials suggested in the Science module and commonly found in the Science laboratory.

After the six weeks of exposure to the two teaching pedagogies, a post-test was conducted to determine if there is a significant difference in the integrated process skills of the respondents.

\section{Results and Discussion}

The data gathered during the six-week exposure period has been subjected to appropriate statistical measures and the results are shown in the succeeding discussions. A paired sample t-test was employed to determine if there is a significant gain in learners' Integrated Science Process Skills. The comparison of the pre-test and post-test means of the participants exposed to SSLS and those who were under the conventional method on their ISPS are presented in the table below.

Table 2

T-test Comparison of the Pre-test and the Posttest means of the control and the SSLS groups

\begin{tabular}{lllllll}
\hline Group & Test & $\mathrm{N}$ & Mean & t-value & p-value & Interpretation \\
\hline \multirow{2}{*}{ Control } & Pre-test & 43 & 11.84 & \multirow{2}{*}{-5.85} & \multirow{2}{*}{0.000} & \multirow{2}{*}{ Significant } \\
& Posttest & 43 & 16.12 & & & \\
\multirow{2}{*}{ SSLS } & Pre-test & 44 & 10.93 & \multirow{2}{*}{-7.24} & 0.000 & Significant \\
\hline
\end{tabular}

Note. $p=0.05$ 
Table 3 shows that the over-all pre-test and post-test mean scores in Integrated Science Process Skills for both SSLS with a mean difference of 7.88 and conventional group with the mean difference of 4.28. They had significantly increased in their ISPS. Such change is significant with a p value of 0.000 at the 0.05 level of significance. This also shows that after the implementation of the two teaching designs, the integrated science process skills of the learners has improved. It can be inferred that though both the SSLS group and the conventional group increased in the ISPS tests, the SSLS group had a higher mean difference than the experimental group.

This result agrees with the study of Morales (2014), that in terms of student achievement, integration implementing SPARK Science Learning System was a success. The integration brought about significant and meaningful learning on the part of the participants. The result of this study also coincides with Al-Mashaqbeh and $\mathrm{Al}$ Khawaldeh in 2006 who investigated the effects of traditional teaching instruction (TI) versus computer-assisted instruction (CAI) using educational software in an educational software design course. Moreover, the results of present study has similar result with Tabassum (2008) which focused on the effect of CAI to secondary students in science revealed that students taught through CAI as supplementary strategy performed significantly better. Students who were under CAI performed better than those who attended the traditional way of teaching science (Hancer \& Tucasen, 2008). Furthermore, a study in Cyprus by Biswas and Chanada in 2011 revealed that there was a significant increase in the achievements and problem solving skills of the students in the experimental group that received the computer based science and technology instruction.

To explicitly detail which specific skill among the five skills of ISPS has gained a better performance, statistical comparison of the pre-test mean and posttest means of the participants under the conventional method on their ISPS through paired sample t-test is presented in table 3.

Table 3

T-test comparison of each skill in ISPS of the control group's pretest and posttest mean scores

\begin{tabular}{lcccc}
\hline \multicolumn{1}{c}{ Skill } & Pretest & Posttest & t-value & p-value \\
\hline Identifying Variables & 1.26 & 2.07 & -3.08 & 0.004 \\
Operationally Defining Variables & 2.4 & 2.72 & -1.15 & 0.258 \\
Formulating Hypothesis & 2.84 & 3.6 & -2.57 & 0.014 \\
Experimenting & 2.79 & 4.7 & -4.62 & 0.000 \\
Interpretation Data & 2.56 & 2.86 & -1.41 & 0.166 \\
\hline
\end{tabular}

Note. $p=0.05$

Table 3 shows that there is a minimal increase in almost all the skills of the conventional group. It could also be observed that designing experiment has the highest increase. The posttest mean and the pre-test mean comparison among the skills of the conventional group in their ISPS show that there is a significant gain in their skills in Identifying variables $(p$-value $=0.004<0.05)$, formulating hypothesis $(p$-value $=0.014<0.05)$ and in experimenting with $(p$-value $=0.000<0.05)$. This implies that the $\mathrm{K}$ to 12 Science Modules could improve the learners' skills of experimenting and formulating hypothesis. This signifies that the usage of the prescribed modules which is also an activity based instruction has the ability to lift specific skills in integrated science process skills.

To explicitly detail of which specific skill among the five skills of ISPS has gain, statistical comparison of the pre-test mean and posttest means of the participants of the SSLS group on their ISPS through paired sample t-test is presented in the table 4. 
Ganeb, M., Montebon, D. R. T., \& Buzon, O.

\section{Table 4}

t-test comparison of each skill in ISPS of the SSLS Group's pre-test and posttest mean scores

\begin{tabular}{lcccc}
\hline \multicolumn{1}{c}{ Skill } & Pre-test & Posttest & t-test & p-value \\
\hline Identifying Variables & 1.48 & 2.98 & -4.14 & 0.00 \\
Operationally Defining Variables & 2.11 & 3.3 & -4.28 & 0.00 \\
Formulating Hypothesis & 2.05 & 3.7 & -5.57 & 0.00 \\
Experimenting & 2.11 & 5.34 & -8.71 & 0.00 \\
Interpreting Data & 3.18 & 3.5 & -0.89 & 0.380 \\
\hline
\end{tabular}

Note. $p=0.05$

Table 5 shows that all the five skills in ISPS increased after the instructional process with the SSLS group. But it could be noted that among the 5 skills in the ISPS, the learners' skills in experimenting greatly improved due to its high increment and with a p-value of $0.000<0.05$. This happens because most learners were exposed to different experiments which they were not used to prior to the instructional process. Statistical test suggests that identifying variables ( $\mathrm{p}$-value $=0.000<0.05$ ), operationally defining variable $(p$-value $=0.000<0.05$ ), formulating hypothesis $(p$-value $=0.000<0.05)$ and experimenting $(p$-value $=0.000<0.05)$ have significantly increased. This implies that utilization of SSLS improve their four skills in integrated science process skills, except in the interpretation of data.

This agrees with the study of Morales, that the performance of the learners whom SSLS was integrated improved significantly but, their ability to interpret the graph was not developed because SPARK immediately or flash a digital data with graph, the students were not engaged in making their own graphs. "Graphing skills of the students and manipulating data may be affected negatively" (Morales, 2014). This result is also supported by the study conducted by Glazer (2011), titled Challenges with graph interpretation. The report insisted that a graph interpretation is a complex and challenging activity. Graph interpretation competence is affected by many factors, including aspects of graph characteristics, the content of the graph and viewers' prior knowledge. The students have may lead to biases and misinterpretation of graphs.

Problem number 2 aimed to find out if there is a significant difference between the post-test means of the students exposed to SSLS and the conventional method on integrated science process skills. To determine if there was a significant difference in learners' ISPS, a statistical comparison of post-test of the participants exposed to SSLS and those who were under the conventional method on their perception in science through independent sample t-test is made as presented in table 5 below.

\section{Table 5}

T-test comparison on the posttest mean score in integrated science process skills

\begin{tabular}{cccccc}
\hline Variable & Group & $\mathrm{N}$ & Mean & t-value & p-value \\
\hline \multirow{2}{*}{ ISPS } & Conventional & 43 & 16.12 & \multirow{2}{*}{-2.195} & 0.031 \\
& SSLS & 44 & 18.81 & & \\
\hline
\end{tabular}

Note. $p=0.05$

Table 6 shows the t-test comparison of the Posttest mean scores in ISPS of the control and the experimental groups. The conventional group has an over-all mean score of 16.12 while the SSLS group has an over-all mean score of 18.64 with a mean difference of 2.52. Statistical analysis shows that the over-all mean score of the control and the experimental groups is significantly different. The result obtained a p-value of 0.031 less than 0.05 level of significance $(p$-value $=0.031<0.05)$. Thus, there is sufficient evidence that utilization of SSLS in teaching Science Investigative Processes is more effective than the conventional group.

The utilization of SSLS to Science Investigative Science lessons had probably provided the suggestion of Valdez (2005) that educators must prepare for a technology-rich future and keep up with change by adopting effective strategies that infuse lessons with appropriate technologies and proposed that multiple and 
complementary research strategies are needed to measure the impact of technology. According to Valdez, technology based learning tool is needed to achieve statistically significant effects. Present study that the schools must make certain effort that there is sufficiently available technology support and maintenance, as well as appropriate software for the learners assisted and catered teachers with a software that would improve the performance of the learners in which the results revealed an improvement in both perception and integrated science process skills. Present study assisted and catered the teacher-researcher with software that would improve the performance of the learners in their perception and integrated science process skills.

The results of this study also agree with Chingos and Whitehurst (2012) whom revealed that there was strong evidence that the choice of instructional materials has large effects on student learning. Most of the time, educational institutions wrongly or blindly choose instructional materials which where most of the time, did not undergo proper evaluation on its impact on the learners performances. Present study revealed that, SSLS could be possible technology based instructional software that would assist science learners improve their integrated science process skills and perception. Specifically, learners designing experiment, class efficacy and critical thinking. The result of this study also coincides with the study of Aurentz, Kerns, and Shibley, 2011. Their study in the Inclusion of modern instrumentation indicated a positive change in students' perception in scientific ideas.

Present study strongly supports the study of Morales (2014), that in terms of student achievement, integration implementing SPARK Science Learning System was a success. Usage of SSLS to SSLS group resulted to significant and meaningful learning on the part of the participants. Research at hand agrees that implementing the SPARK Science Learning System could "touch grounds on learning and innovation skills, which focus on creativity, critical thinking, communication and collaboration". Furthermore, Morales emphasizes the use of the SPARK Science learning system gives students more opportunities to develop skills related to information, media and technology. Present study abled to identify a specific skill in integrated science process that it could enhance which is identifying variable in an experiment. Aside from that, learners' perception in science improved the learners' meaningful engagement and relationship with students and teachers. This result shows that SPARK could possibly, a tool that would assist in the full implementation of the K to 12 curriculums. Morales (2014) asserted that there should be a meaningful integration in the curriculum to improve learners' achievement. Present study opted to utilize SSLS in teaching Science Investigative Processes in Diversity of Material in the Environment through the use of SSLS sensors to the experimental respondents in the duration of this research implementation. Morales (2014) further suggested making an experimental study on Science process skills.

Meanwhile, this study disagrees with Barlis and Fajardo (2013) which revealed that there was no significant difference on the posttest means with the CAI and the traditional method of teaching. ISPS has five different skills. To discuss in detail which specific skill in the posttest of the conventional and the experimental group, a statistical comparison of the posttest means of the participants on their ISPS through independent sample t-test was made and the result is presented in the table 6 below.

\section{Table 6}

T-test comparison in posttest of the individual skills' of the control and the SSLS groups

\begin{tabular}{lcccc}
\hline \multicolumn{1}{c}{ Skill } & $\begin{array}{c}\text { Conventional } \\
\text { Group }\end{array}$ & $\begin{array}{c}\text { SSLS } \\
\text { Group }\end{array}$ & t-value & p-value \\
\hline Identifying variables & 2.07 & 2.98 & -2.28 & 0.025 \\
Operationally Defining Variables & 2.72 & 3.3 & -1.73 & 0.087 \\
Formulating Hypothesis & 3.6 & 3.7 & -2.94 & 0.769 \\
Experimenting & 4.7 & 5.34 & -1.36 & 0.178 \\
Interpretation of Data & 2.86 & 3.5 & -1.97 & 0.052 \\
\hline
\end{tabular}

Note. $p=0.05$ 
Table 7 shows that the posttest's mean difference in each skill of the ISPS. All the skills showed that the SSLS group is higher than the conventional group. The posttest comparison between the conventional and the experimental group shows that identifying variable has the highest mean difference. Statistical analysis suggests that utilization of SSLS in teaching Science Investigative Process has the best effect in the skill of identifying variable.

The present result of the study agrees on Hafizan and Shahali (2010) that Integrated Science Process Skills are more complex than the basic science process skills. Science learners should possess these skills in in their higher year (Hafizan \& Shahali, 2010). Integrated science process skills could not be acquired immediately. This should be integrated in most of the science experiments so that these skills would be imbibed and developed as they learn science through different laboratory experiments. Teachers need to select curricula which emphasize science process skills. In addition they need to capitalize on opportunities in the activities normally done in the classroom.

The present study also agrees with Al-Mashaqbeh and Al Khawaldeh in 2006. They investigated the effects of traditional teaching instruction (TI) versus computer-assisted instruction (CAI) using educational software. The educational software design course Educational software was developed to investigate the difference between two groups that were given a pre-test and a post-test to measure their achievements in the course. Their result showed that students with software assistance gained a higher mean score.

This study supports the idea of Bajah (2000) that process skills in science are very important in the formal presentation of science to the learners. There is a strong belief that students who are properly introduced to science through process skills will find the skills throughout their lives useful.

SPARK Science Learning System certainly assists $21^{\text {st }}$ century learners. The device that immediately gives digital data could enhance technological literacy among learners. Developing technologically literate individuals is one of the aims of $\mathrm{K}$ to 12 Basic Enhanced Science Curriculum. Science process skills are one of the most important components of science curricula in all levels (Langasse, 2006). ISPS are composed of identifying variables, operationally defining variables, formulating hypothesis, experimenting and interpreting data.

\section{Conclusions and Implications}

Several conclusions were drawn from the findings of this research. The utilization of SPARK Science Learning System in the prescribed modules in the K-12 Basic Enhanced Science Curriculum effectively improved the learners' integrated science process skills. The SSLS group performed better in their integrated science process skills than the conventional group. Utilization of SSLS could help Filipino learners enhance and develop their technological literacy through inquiry-based learning. SSLS could be utilized in different science lessons to improve the teachers' ability of integrating technology as their instructional tools in facilitating the $21^{\text {st }}$ century learners.

This study affirms the method utilized by science teachers to integrate technology in their teaching to be effective in molding students' integrated science process skills. The use of SPARK in the classroom can 'spark' students' interest to learn science better. Moreover, SSLS could possibly assist in the full implementation of the $\mathrm{K}$ to 12 curriculum in the Philippines. Integrated Science Process Skills are needed by the $21^{\text {st }}$ century learners as the newly adapted Enhanced Basic Education Curriculum requires activity oriented lessons. The usage of SSLS in several activities certainly contributes to the development of ISPS among learners. A technological literacy and a strong foundation in ISPS may engage students to inquiry based science learning. The enrichment of technological literacy among the $21^{\text {st }}$ century learners would be attained if the educators will focus on the improvement of the learning tools or gadgets in the classroom which the SSLS could provide. The well-developed integrated science process skills among learners initiate and encourage them to perform better in several laboratory activities. Being equipped with these skills, they may confidently execute several investigative processes with deeper understanding through science inquiry-based learning. 
Utilization of SPARK Science Learning Systemand its effect on science process skills of students in science

Also, the efforts of the government to support science teachers by providing the SPARK Science Learning System is not in vain for it truly helps the students as well as the teachers. Though SPARK Science Learning System is a very expensive device, its worthiness is has been proven in this research.

\subsection{Recommendations}

This research suggest the following to educators and researchers:

$>$ SSLS should be integrated in the K-12 Enhanced Science Curriculum.

$>\quad$ School heads should encourage the science teachers to include SSLS in their lessons

$>\quad$ Create a model of how SSLS can be meaningfully be integrated in the Enhanced Science Curriculum

$>\quad$ Conduct a similar studies but using other cognitive skills like problem solving or other lessons such as force and motion where SSLS provides as well;

$>\quad$ Conduct a study that includes longer exposure to SSLS and determine if this can change the result of the present research.

$>\quad$ Investigate whether integrated science process skills and science perception are correlated variables

\section{References}

Abante, M. (2006). Computer-aided instructional materials in teaching statistics in the tertiary level. Unpublished Masteral thesis, Eulogio Amang Rodriguez Institute of Science and Technology, Manila.

Al-Mashaqbeh, I. F., \& Al Khawaldeh, S. A. (2009). Effects of using educational software in the Computer-Assisted Instruction (CAI) method to increase adult learners' achievement. Malaysian Journal of Distance Education, 11(2), 85-95.

Bajah, S. T. (2000). Early learning science series for Africa. Retrieved from http://library.unesco-iicba.org/English/SECONDARY_SCIENCE_SERIES/science_lessons/2_process skills.htm

Barlis, J. M., Jr., \& Fajardo, J. D., III (2013). Effectiveness of simulation and computer assisted instruction (CAI) on the performance of students. International Journal of Applied Physics and Mathematics, 3(1), 82-86. http://dx.doi.org/10.7763/IJAPM.2013.V3.180

Bernardo, A. B. I. (2002). Teachers, the problem of learning, and reform in math and science education. Ateneo de Zamboanga Journal of Multidisciplinary Studies, 2(1), 1-20.

Bernardo, A. B. I. (2004). Constructivism, curriculum and the challenges in transforming science education in the Philippines. Learning Edge, 4, 1-33.

Clark, J. (2010). Best practices research summary. Sun Associates 2010. Retrieved from http://www.sun-associates.com

DepED, NERTC. (2014). Results of National Achievement Tests. Retrieved http://www.netrc.sysportal.net

Fonseco, J. M., \& Conboy, J. E. (2006). Secondary student perceptions of factors affecting failure in Science, Eurasia Journal of Mathematics, Science and Technology Education, 2(2), 82-95.

Glazer, N. (2011). Challenges with graph interpretation: A review of the literature studies in Science Education. School of Education, University of Michigan, Ann Arbor MI.

Hafizan, E., \& Shahali, M. (2010). Development and validation of a test of integrated science process skills. Faculty of Education, Universiti Kebangsaan Malaysia, Bangi, Selangor.

Hançer, A. H., \& Tuzemen, A. T. (2008). A research on the effects of computer assisted science teaching. World Applied Sciences Journal, 4(2), 199-205.

Huppert, J., Lomask S. M., \& Lazarorcitz, R. (2002). Computer simulations in the high school: students' cognitive stages, science process skills and academic achievement in microbiology. International Journal of Science Education, 24(8), 803-821. http://dx.doi.org/10.1080/09500690110049150 
Ganeb, M., Montebon, D. R. T., \& Buzon, O.

Langasse, P. (2006). The Columbia Encyclopedia (6 ${ }^{\text {th }}$ ed., pp. 66-69). University of Oslo, Norway.

Mei, G.T., Kaling, C., Xinyi C. S., Sing J. S., \& Khoon, K. S. (2007). Promoting science process skills and relevance of Science through Science Alive Program. Paper presented at Redesigning Pedagogy: Culture, Knowledge and Understanding Conference. Singapore.

Mishra, P., \& Koehler, M. J. (2006). Technological pedagogical content knowledge: A new framework for teacher knowledge. Teachers College Record, 108(6), 1017-1054. http://dx.doi.org/10.1111/j.1467-9620.2006.00684.x

Morales, M. P. (2014). Influential factors in modelling SPARK science learning system. International Journal of Learning, Teaching and Educational Research, 4(1), 36-50.

Osborne, J., \& Dillon, J. (2008). Science education in Europe: Critical reflections. The Nuffield Foundation. London.

Padilla, M. J. (1990). Research matters - to the science teacher. The science process skills. National Association for Research in Science Teaching. Retrieved from http://www.educ.sfu.ca/narstsite/publications/research/skill.htm

PASCO. (2013). Data logging $21^{\text {st }}$ century inquiry-based science learning SPARK science. Roseville, California, USA.

Richey, R. C., Silber, K. H., \& Ely, D. P. (2008). Reflections on the 2008 AECT definitions of the field. TechTrends, 52(1), 24-25. http://dx.doi.org/10.1007/s11528-008-0108-2

Slagut, B. (2007). The effects of computer assisted instruction along with internet for 5th grade primary school students acquisition in Science and Technology lessons light and voice unit. Unpublished Masteral Thesis, Cukurova University Institute of Social Sciences, Turkey.

Stokstad, P. A. (2011). SPARK science learning system: The message of a founder. Retrieved from http://www.pasco.com

Tabassum, R. (2004). Effect of computer aided assisted instruction (CAI) on secondary school students achievement in science. Retrieved from http://eprints.hec.gov

Valdez, G. (2005). Technology: A catalyst for teaching and learning in the classroom. Retrieved, Feb. 9, 2014, from http://www.edu2.georgetowncollege.edu

Weiss, I. R., \& Pasley, J. D. (2004). What is high-quality instruction? Retrieved from http://www.nwrel.org

Yakar, H. (2005). The effects of computer assisted teaching on student's success in teaching Newton's movement laws. Institute of Sciences, Turkey.

Yesilyurt, M. (2011). Meta-analysis of the computer assisted studies in physics: A sample of Turkey. Energy Education Science and Technology Part B. Social and Educational Studies Social and Educational, 3(2), 173-182. 